\title{
AIDS and the general practitioner: views of patients with HIV infection and AIDS
}

\author{
Michael B King
}

\begin{abstract}
An unselected series of outpatients infected with the human immunodeficiency virus (HIV) who attended two London hospitals were interviewed to assess their relationship with their general practitioner. Although most of the 192 patients were registered with a general practitioner, the doctors of only one half knew of the diagnosis. Patients feared a negative reaction from their general practitioner or were concerned about confidentiality. Although those who had told their doctor had received favourable reactions, few general practitioners attempted to counsel or educate their patients.

The patients who previously had been open about their homosexuality were not more likely to have told their general practitioner of their HIV infection. Although most did not think that general practitioners were well informed about AIDS, half of the patients wished that general practitioners could take a bigger part in their care.
\end{abstract}

\section{Introduction}

As the number of people with the human immunodeficiency virus (HIV) grows and more and more people worry about possible exposure to the virus there is a pressing need for understanding and willingness to treat problems that are related to HIV infection in general practice. ${ }^{1.3}$ Reports that patients with HIV have been rejected by general practitioners continue to circulate in the media, and yet there has been little assessment of what general practitioners are doing for these patients. If doctors are to respond effectively to the psychological problems faced by patients they must know something about the groups of people who are known to be at risk, particularly about gay lifestyles $^{t+h}$ and the subculture of intravenous drug abuse. Patients' perceptions of their general practitioners, accurate or not, is an important determinant of their use of primary care.

This paper reports the findings of a study of patients' perceptions of general practitioner services, particularly of the management of psychological and physical complaints and issues concerning confidentiality

\section{Methods and results}

Outpatients with HIV infection who were attending two London teaching hospitals were interviewed after they had given informed consent. Consecutive patients took part at clinic 1 , while at the busier clinic 2 after each interview was completed the next available patient was asked to participate. I interviewed all of the subjects. After demographic data were collected patients were given a semistructured interview to elicit information on the following: (a) HIV: reasons for test; openness; reactions of others. (b) Sexual history: orientation; openness; partners. (c) General practice: details of registration; contact with general practitioner; openness concerning HIV, sexuality, and drug taking; perceptions of the general practitioner's ability concerning medical and psychological issues; perceived attitude of doctor and recommendations for improving care.

\section{Response rates, demography, and diagnosis}

Of 206 patients who were approached, 192 (189 men and three women) agreed to interview (figure). The

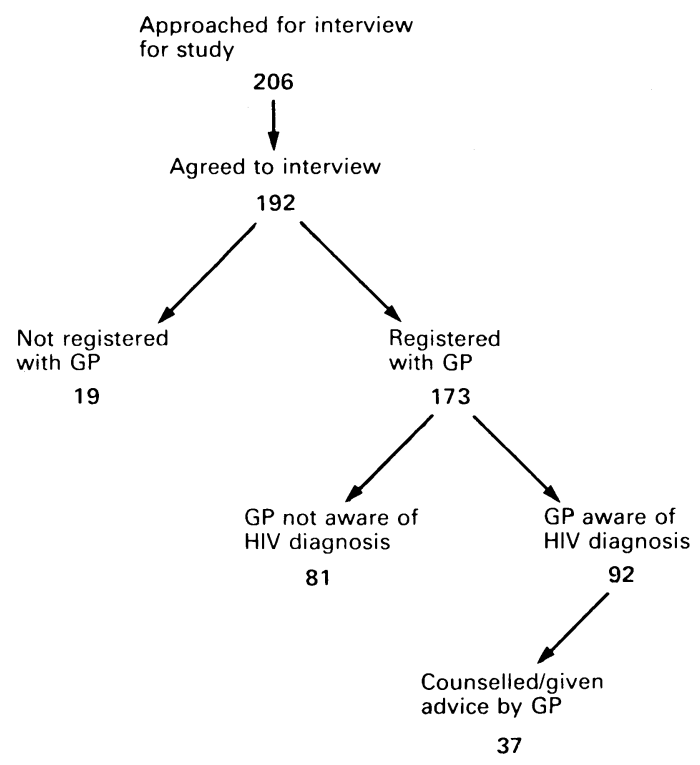

Flow chart of patients' contacts with general practitioner

mean age was 35 , most were white, and $106(55 \%)$ were in social classes I and II. ' For 108 patients the diagnosis was made at the clinic they now attended. Sixty five were HIV antibody positive but well, 64 had additional signs or symptoms (41 persistent generalised lymphadenopathy, 23 AIDS related complex), and 63 had the full syndrome of AIDS. Table I shows the significant differences between the two populations from clinics 1 and 2 .

TABI.E I-Differences between the two clinic populations

\begin{tabular}{lcc}
\hline & Clinic 1 Clinic 2 \\
\hline Social class: & 19 & 87 \\
$\quad$ I \& II & 29 & 57 \\
3 and below & & \\
Diff $=21 \% ; 95 \%$ confidence interval $=4 \cdot 7$ to $37 \cdot 3 ; \%^{2}=6 \cdot 32$, & & \\
$\mathrm{df}=1, \mathrm{p}<0 \cdot 02$ & 38 & 68 \\
Diagnosis: & 10 & 76 \\
$\quad$ HIV or persistent generalised lymphadenopathy & & \\
AIDS related complex or AIDS & & \\
Diff $=32 \% ; 95 \%$ confidence interval $=15 \cdot 7$ to $48 \cdot 3 ;$ \\
$\%^{2}=14 \cdot 85, \mathrm{df}=1, \mathrm{p}<0 \cdot 001$
\end{tabular}

Institute of Psychiatry, SE5 8AF

Michael B King, MRCGP senior lecturer 
General practice involvement in HIV diagnosis

Nineteen patients were not registered with a family doctor, 18 of whom were attending the larger and more well known clinic 2 . The doctor reportedly knew of the HIV diagnosis in 92 subjects, of whom 56 had told the general practitioner themselves. The doctors knew of the diagnosis in the others after having recommended or performed an HIV test, or from information from a third party, usually a hospital after the patient was discharged. In seven cases the doctor had been informed by the sexually transmitted disease clinic. The general practitioner was more likely to be aware of the diagnosis if the patient had AIDS related complex or AIDS ( $\operatorname{diff}=34 \% ; 95 \%$ confidence interval $=20$ to $48 ; \chi^{2}=22 \cdot 12, \mathrm{df}=1, \mathrm{p}<0.0001$ ) or where the diagnosis had been known for more than six months $\left(\chi^{2}\right.$ (Yates's) $=5.43, \mathrm{df}=1, \mathrm{p}<0.02$ ). The doctor had referred 17 patients either for diagnosis or for a test; 11 of these had been counselled beforehand, usually on the implications of testing together with medical information about AIDS. One man claimed his general practitioner had arranged the test without his knowledge.

Patients whose diagnosis was known to the general practitioner

Thirty seven patients had received some counselling or been given information since the test; 10 had been referred to the Terrence Higgins Trust, to mental health professionals, or to a clinic for sexually transmitted diseases. In seven cases general practitioners had provided counselling for both the patient and a close friend or relative and in six cases for a close friend or relative. Most subjects considered themselves well

TABLE II-Patients' views where general practitioner was aware of HIV diagnosis $(n=92)$

\begin{tabular}{lc}
\hline & No $(\%)$ \\
\hline General practitioner helpful for worries/anxieties about HIV & $28(30)$ \\
General practitioner routinely inquires after their health HIV & $32(35)$ \\
General practitioner interested in help received from clinic & $42(6)$ \\
General practitioner considered knowledgeable about AIDS & $48(52)$ \\
Satisfied with general practitioner & $78(85)$ \\
\hline
\end{tabular}

informed about safer sex and did not expect this information from the doctor, though 14 received some information about this and the medical aspects of AIDS. There was no link between the time since diagnosis and the likelihood of having received counselling from the general practitioner. Twenty six patients $(28 \%)$ thought that their doctor was more helpful and empathetic since their HIV state was known. In only two cases were the general practitioners' reactions hostile, although in a further three the doctor had inadvertently distressed the patient by actions or comments. Table II summarises the patients' views.

\section{Patients whose doctor was not informed}

Eighty one subjects $47 \%$ of those registered with a general practitioner) said that their doctor was unaware of their HIV state (figure), although 26 of these thought the doctor should know, either for help with medical problems or for the doctor's own protection. Those patients who thought it was not important for the general practitioner to know claimed that this was because hospital staff were more expert, that they had easy access to a clinic, or that they had no confidence in their general practitioner.

When asked why they had expressly not contacted their doctor, however, their reasons emphasised fear of a negative reaction or outright rejection, fear of a possible breach of confidentiality, a belief that the doctor was inexperienced in problems associated with HIV infection, or a general feeling of stigma. But 10 of these 81 subjects claimed that they would attend their general practitioner for complaints that they feared might be related to HIV, even though the doctor was not informed of their HIV state, and 27 said that they would continue to see their doctor for complaints they believed were unrelated to HIV.

When patients were advised by the clinic not to tell the general practitioner (table III) it was usually out of fear of possible rejection by the general practitioner or lack of confidentiality, particularly regarding insurance.

TABLE III-Advice given by clinic staff regarding the general practitioner to 192 patients

\begin{tabular}{lc}
\hline & $\begin{array}{c}\text { No of } \\
\text { patients }\end{array}$ \\
\hline General practitioner reportedly not mentioned & 130 \\
Recommended to inform general practitioner & 22 \\
General practitioner mentioned, no particular advice & 22 \\
Advised not to tell general practitioner & 18 \\
\hline
\end{tabular}

Patients not registered with a primary care physician

Most of the 19 patients who were not registered with a doctor thought that a general practitioner could provide nothing over and above the care provided by the clinic for sexually transmitted diseases. Four had refused to register with a doctor for fear of lack of confidentiality and two because of fear of rejection.

Sexual orientation, intravenous drug use, and disclosure to the doctor

Only five patients claimed that their relationship with their doctor had deteriorated since their sexual orientation was known (table IV). Most of those who

TABLE IV-Sexual orientation, intravenous drug use, and disclosure to the doctor

\begin{tabular}{lr}
\hline & No \\
\hline Men $(\mathrm{n}=189):$ & \\
Homosexual bisexual & 43 \\
Heterosexual & 1 \\
Transsexual & 1 \\
Not known & \\
Disclosure to general practitioner of homosexuality/bisexuality & 71 \\
$\quad(\mathrm{n}=126):$ & 47 \\
Sexual orientation revealed before HIV diagnosis & 8 \\
General practitioner knew of sexual orientation after HIV diagnosis & \\
Patient assumed general practitioner knew & 8 \\
Intravenous drug users $(\mathrm{n}=12):$ & 3 \\
Homosexual/bisexual men & 1 \\
Heterosexual men & 1 \\
Women & 5 \\
Current drug user & \\
Informed general practitioner of drug use &
\end{tabular}

had not told their general practitioner of their homosexuality thought that it was irrelevant to their medical care or had little contact with the doctor. Few feared lack of confidentiality or a negative reaction by the doctor. Patients who had been open with their general practitioner about their homosexuality were no more likely to be satisfied with their doctor's ability or eager for doctors to be more concerned in HIV issues. Nor were they more likely subsequently to be open about the HIV infection.

Drug users (table IV) were no more or less likely than other patients to have told their general practitioner of their HIV infection.

\section{General views about general practice-all subjects}

Eighty (44\%) of the 183 homosexual or bisexual men reported that they would prefer to attend a homosexual doctor, principally from a belief that such a doctor 
would be more understanding of gay lifestyles, more knowledgeable about AIDS, and more willing to treat HIV patients. Twenty four subjects claimed that their doctors were homosexual. Most (103) homosexual or bisexual men, however, had no such preference, believing the doctor's attitude was more important than his or her sexuality.

Although of the 192 subjects $77(40 \%)$ did not think there were any potential disadvantages in a general practitioner knowing of their HIV state, the remainder were concerned about confidentiality of practice records, particularly for insurance purposes, and the possibility of a negative reaction from the doctor. Only seven felt that they might be at risk of being given the wrong treatment by a doctor who was not familiar with HIV infection. Although 38 subjects thought that general practitioners would notify a government department of HIV patients on their list, most knew that HIV infection was not notifiable. Most of the patients had little faith in the confidentiality of general practice records (table $\mathrm{V}$ ).

TABLE V_Patients' (192) rating of security/confidentiality of records

\begin{tabular}{lr}
\hline & No \\
\hline Sexually transmitted disease clinic records most secure & 133 \\
General practitioner, sexually transmitted disease clinic, and hospital & \\
records all equal & 28 \\
General practitioner records most secure & 22 \\
Hospital ward notes most secure & 3 \\
Noopinion & 6
\end{tabular}

Ninety nine subjects thought that general practitioners should play a bigger part in the treatment of their patients with HIV, although paradoxically these patients were no more likely to have informed their general practitioner of their diagnosis. Only 22 said definitely that general practitioners should be less concerned in treatment. Almost all (187) wanted most of their care to be undertaken by the hospital clinic

\section{Discussion}

Although it was impossible to corroborate the statements made by the patients in this survey, it remains true that patients' perceptions of their doctor, whether they are accurate or inaccurate, will determine the use made of medical services. ${ }^{+8}$ Although this sample of patients was of high social status and was skilled at using the health service in seeking treatment for HIV infection, only half reported that their general practitioner was aware of the diagnosis. Even fewer had told their general practitioner directly, and most of those who had not involved their doctor had no intention of doing so. Patients needlessly expected a negative reaction from general practitioners but also thought that their doctor's records were not confidential. Doctors may not be fully aware how crucial confidentiality is for many patients.

Only very few subjects whose diagnosis was known to the general practitioner had received any psychological or educational support, though in a few cases doctors were particularly helpful and almost never rejected patients. If general practitioners are to do more for their patients with HIV ${ }^{2}$ particularly through counselling and prevention, ${ }^{13}$ they will need to take a more active role and cannot assume that patients will receive all their help from clinics for sexually transmitted diseases or are well informed about their condition. Over half of this sample wanted general practitioners to take a greater part in the care of patients with HIV.

Seventy one $(39 \%)$ of the homosexual patients had told their general practitioner of their sexual orientation before becoming infected with HIV, a somewhat lower proportion than that reported for homosexual patients in the United States. ${ }^{+}$Furthermore, in contrast to the American results, these patients expressed no greater satisfaction with their doctors than those who had not been open with their doctors. This was possibly the reason why they were subsequently no more likely to have told their general practitioner of their HIV infection than those patients whose sexuality was not known to their general practitioner. Doctors need to be sensitive to the sexual orientation of their patients ${ }^{9}$ and be able to discuss sexual matters as they would with heterosexuals." " Almost half of the gay men would have preferred a homosexual doctor, perhaps reflecting their lack of confidence in the attitudes of heterosexual general practitioners. Most, however, were more concerned that their doctor should simply accept their lifestyle. Doctors may have to deal with their own reactions to homosexuality ${ }^{t *}$; attitudes to AIDS have been shown to be more closely correlated with attitudes to homosexuality than even knowledge of the disease itself. ${ }^{12}$

A proportion of patients seek help from their doctors without informing them of their HIV infection, which may lead to misunderstanding and mismanagement. ${ }^{13}$ It is also of concern that clinic staff did not encourage patients to be frank with their general practitioner. Clinics for sexually transmitted diseases are in an anomalous position in the health service because they act as a primary care facility and thus have no need to inform the general practitioner of their involvement. The BMA has recently upheld the sanctity of such patient-doctor confidentiality. ${ }^{14}$ If general practitioners are to have clinical responsibility for patients who are cared for in the community ${ }^{2}$ they will have to play a bigger part in clinical decision making.

If general practitioners become more knowledgeable about homosexual lifestyles and the medical aspects of AIDS and give more attention to confidentiality patients and sexually transmitted disease clinics will be encouraged to regard them as part of the treatment team.

I thank Dr Paul Williams, Dr Deborah Sharp, and Mrs Brenda Robinson of the Institute of Psychiatry for help and advice; the consultant medical staff of the Lydia Clinic, St Thomas's Hospital and the John Hunter Clinic, St Stephen's Hospital, London, for allowing access to their patients; and all the clinic staff for their patience and help.

This work was completed under the direction of Professor Michael Shepherd, director of the general practice research unit, Institute of Psychiatry, and was funded by the DHSS.

1 Bucknall A. Regional patterns of AIDS and HIV infection. $\mathcal{F} R$ Coll Gen Pract 1986;36:491-2.

Adler MM. Care for patients with HIV infection and AIDS. Br Med 7 1987;295:27-9.

3 Anonymous. AIDS, HIV and general practice. $\mathcal{J} R$ Coll Gen Pract 1987;37 $289-90$.

4 Dardick L, Grady KE. Openness between gay persons and health profe sionals. Ann Intern Med 1980;93:115-9.

5 Dilley JW, Ochtill HN, Perl M, Volberding MD. Findings in psychiatric consultations with patients with acquired immune deficiency syndrome. $A m$ f Psychiatry 1985;142:82-6.

6 Wachter RM. The impact of the acquired immune deficiency syndrome on medical residency training. $N$ Engl 7 Med 1986;314:177-80.

7 Goldthorpe J, Hope K. The social grading of occupations: a new approach and scale. London: Oxford University Press, 1974.

8 Klein M. Pfeffer D. Homosexuality and the physician. New Physician 1985; Sept 43-4.

9 Cassens BJ. Social consequences of the acquired immune deficiency syndrome. An Intern Med 1985;103:768-71.

10 Leach G, Whitehead A. AIDS and the gay community: the doctor's role in counselling. Br.Med f 1985:290:583.

11 Owen WF. The clinical approach to the homosexual patient. Ann Intern Med 1980;93:90-2.

12 Morton AD, McManus IC. Attitudes to and knowledge about the acquired immune deficiency syndrome: lack of a correlation. Br Med $\mathcal{F}$ 1986;293: immune deficiency syndrome: lack of a correlation. Br Med f 1986;293:

13 Norell JS. In aid of doctors suffering from complaints about AIDS. Br Med 7 1986;293:1213-5

$14 \mathrm{King} \mathrm{MB}$. AIDS and the general practitioner: psychosocial issues. Health Trends 1987:19:4):1-2.

Accepted 18.April 1988 